\title{
Comparative evaluation of oral clonidine and midazolam as premedication on preoperative sedation and laryngoscopic stress response attenuation for the patients undergoing general anaesthesia
}

\begin{abstract}
Anjan Das,
Tushar Kanti Saha1, Saikat Majumdar', Rahul Deb Mandal ${ }^{3}$, Anindya Mukherjee ${ }^{2}$, Subrata Kumar Mandal

Department of Anaesthesiology, S. D. Medical College,

${ }^{1}$ Community Medicine and

${ }^{2}$ Anaesthesiology, Nil Ratan Sircar Medical College, Kolkata,

${ }^{3}$ Gynaecology and Obstetrics,

Burdwan Medical College,

Burdwan, West Bengal, India
\end{abstract}

Address for the Correspondence: Dr. Anjan Das,

174, Gorakshabashi Road, Royal Plaza Apartment (4 $4^{\text {th }}$ Floor,

Flat No-1), Nagerbazar, Kolkata - 28, India.

E-mail: anjan2k8@yahoo.com

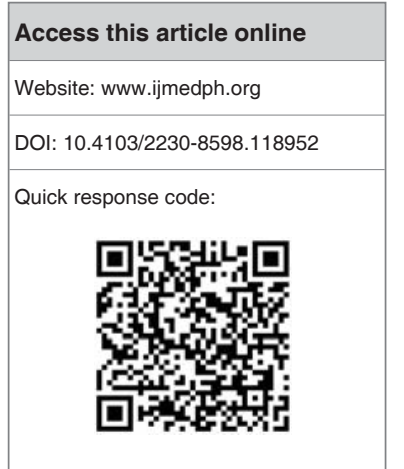

\begin{abstract}
Context: Laryngoscopy and endotracheal intubation is associated detrimental hemodynamic changes like rise in blood pressure (BP), heart rate (HR) leading to adverse cardiological outcome specially in susceptible individuals. Aims: To compare the blood pressure (BP) and heart rate (HR) changes during laryngoscopy and endotracheal intubation as well as to evaluate the preoperative sedation status between oral clonidine and oral midazolam as premedication for the patients undergoing general anesthesia (GA). Settings and Design: Fifty patients between 18 and 60 years of age of either sex of American Society of Anesthesiologists (ASA) Grade I and II undergoing GA were randomly divided into two equal groups of 25 patients each. Group-C patients received clonidine $4 \mathrm{mcg} / \mathrm{kg}$ orally and Group-M patients received $0.5 \mathrm{mg} / \mathrm{kg}$ midazolam orally as premedication. Materials and Methods: After measuring baseline hemodynamic parameters patients of both groups received premedication. Preoperative sedation was assessed $2 \mathrm{hr}$ after premedication administration. Standard anesthetic technique was followed. Hemodynamic (HR, BP) parameters were noted baseline, immediately after laryngoscopy and intubation and 5 min after intubation to observe the stress response. Results and Statistical Analysis: A significant difference in pre-operative sedation between two groups $(P<0.05)$ and midazolam (group $M)$ produced significantly better sedation than clonidine (group $C$ ). Laryngoscopic stress response in group $C$ was still at a lower level than baseline values and significantly $(P<0.005)$ less than group M. Conclusions: Oral midazolam is more effective in producing preoperative sedation than oral clonidine while on the contrary oral clonidine is more efficacious in reducing laryngoscopic stress response than oral midazolam. Laryngoscopy and intubation was better controlled by oral clonidine than midazolam.
\end{abstract}

Key words: Clonidine, endotracheal intubation, general anesthesia, laryngoscopy, midazolam

\section{INTRODUCTION}

A major goal of anesthesiologist is to assure attenuation of the hemodynamic and autonomic responses to noxious stimuli, while still preserving adequate circulatory function. The demand of patients is to face the operation with calm and confidence, without anxiety. In modern anesthesia practice, for general anesthesia (GA) Laryngoscopy and endotracheal intubation are done frequently which is invariably associated with rise in heart rate (HR), arterial blood pressure (BP), and occasional disturbance of cardiac rhythm. These hemodynamic responses arise as a form of sympathoadrenal reflex. This adrenergic stress response is extremely harmful in patients with cardiac disorders, old age, hypertensive patients, and neurological disturbances.

A number of drugs have been tried for attenuation of the cardio-vascular response. The list includes topical lignocaine $e^{[1]}$, intravenous (IV) lignocaine ${ }^{[2]}$, IV Hydralazine ${ }^{[3]}$, volatile anesthetic agents ${ }^{[4]}$, narcotic analgesics ${ }^{[5-7]}, \beta$-adrenergic blockers, ${ }^{[8,9]}$ and vasodilators ${ }^{[10,11]}$ like nitroglycerine and nifedipine, etc. 
Midazolam, a benzodiazepine, is the most commonly used premedication because of its anxiolytic and hypnotic effect, a short elimination half life and high clearance, better anterograde amnesia, and minor effect on hemodynamic and respiratory inhibition compared to other benzodiazepines.

Recently, clonidine has been utilized as a preoperative medication to provide anxiolysis, sedation, analgesia, hemodynamic stability, control of salivation, and antiemetic effects. It also possesses sedative, anesthetic, and analgesic sparing properties that reduce the dosages of other medications.

Sedation is another vital goal of premedication ${ }^{[12-14]}$. In a comparative study, oral clonidine appeared to be superior to oral midazolam in producing effective preoperative sedation. ${ }^{[15]}$ In contrary another study showed that oral midazolam was superior to clonidine in relieving preoperative anxiety and was preferred by the child's parents. ${ }^{[16]}$

So, an endeavor was made to evaluate the effects of oral clonidine $4 \mathrm{mcg} / \mathrm{kg}$ on hemodynamic changes during laryngoscopy and intubation, preoperative sedation, and side effects, in comparison to oral Midazolam $0.5 \mathrm{mg} / \mathrm{kg}$ when both are given 2 hours prior to induction of GA.

\section{Objectives}

- To compare the BP, HR changes during laryngoscopy and endotracheal intubation between oral clonidine and oral midazolam for the patients undergoing GA

- To evaluate the preoperative sedation status between these two drugs

- To identify the complications, if any.

\section{MATERIALS AND METHODS}

This single center, prospective randomized, single blinded, parallel Group study was carried out in the Department of Anesthesiology after obtaining permission from the Institutional Ethical Committee in the period between February 2009 and April 2010.

\section{Selection criteria Inclusion criteria}

A total of 50 adult patients of either sex aged between 18 and 60 years of ASA status I and II scheduled to undergo different surgical procedure where duration of surgery and anesthesia is expected to be less than 2 hours were included in this study after obtaining informed consent from each patient.

\section{Exclusion criteria}

Patients of ASA status III, IV with signs and symptoms of serious cardiovascular, pulmonary, renal, hepatic or neurological disease, systemic or local infection, diabetes mellitus, ischemic heart disease, hypertension, malignancy, hemodynamically unstable, hypersensitivity to study drugs, pregnancy were excluded from the study.

\section{Technique}

Sample size was estimated using the PS (Power and sample size calculation version 2.1.30 Feb'2003). The sample size required for correctly rejecting the null hypothesis (of equal mean requirement of propofol dose for induction) with a probability of $90 \%$ (i.e. power 0.90 or $90 \%$ ) was based on the following assumptions. This calculation assumed a standard clinically important difference of $10 \mathrm{mg}$ for the propofol dosing with $\alpha=0.05$ or $5 \%$ (probability of type I error). It was estimated that 23 subjects per group would be required to detect a difference of $10 \mathrm{mg}$ in propofol requirement between the two groups. Hence, the recruitment target had been kept as 25 subjects per group and total number came to $50(n=50)$.

\section{Anesthesia technique}

Following a detailed history and physical examination all patients were instructed not to consume solid food after midnight on the day of surgery, but clear fluids were permitted till 4 hours before the scheduled time of operation. Patients were explained about the anesthetic technique, premedication administration, and the interpretation of sedation score.

On the day of operation, the baseline hemodynamic parameters were measured again in the pre-operative room before giving premedication. According to the body weight of the patient, calculated amount of drugs were given. Hemodynamic parameters (HR, $\mathrm{BP}, \mathrm{SpO}_{2}$ ) were studied in preoperative room. If fall in oxygen saturation $\left(\mathrm{SpO}_{2}<90 \%\right)$ detected, then $\mathrm{O}_{2}$ were delivered by nasal cannulae.

Group-C $(n=25)$ Clonidine group. Oral clonidine $4 \mathrm{mcg} / \mathrm{kg}$ given 2 hours prior to induction of GA. Group-M $(n=25)$ Midazolam group. Oral Midazolam $0.5 \mathrm{mg} / \mathrm{kg}$ given 2 hours prior to induction of GA.

Preoperative sedation was assessed 2 hours after premedication in preoperative room. Then patients were taken to operation theatre. Standard anesthesia technique was followed in every case. Pre oxygenation for 5 minutes, Injection fentanyl $1 \mathrm{mcg} / \mathrm{kg} \mathrm{IV}$ and Injection propofol administration up to loss of verbal command were administered. Mean dose of propofol were measured. Injection atracurium $0.5 \mathrm{mg} / \mathrm{kg}$ IV was used for intubation. After 3 min of Atracurium administration, laryngoscopy and intubation were performed. Anesthesia was be maintained with nitrous oxide $66 \%$ in oxygen and isoflurane up to 1-2 MAC. Intermittent dose of atracurium and fentanyl was used for muscle relaxation and analgesia, respectively. At the end of surgery, anesthetic agents were discontinued and neuromuscular blockade was reversed by injection neostigmine $0.05 \mathrm{mg} / \mathrm{kg}$ along with glycopyrrolate $0.01 \mathrm{mg} / \mathrm{kg}$ after fulfilling the criteria for extubation.

Hemodynamic parameters, that is, noninvasive BP monitoring for systolic blood pressure (SBP), diastolic blood pressure (DBP), mean arterial pressure (MAP), and HR were noted (2 hours after premedication, just after induction, immediately after laryngoscopy and intubation and 5 minutes after intubation). Patients were 
monitored for any side effect upto 12 hours after completion of procedure.

Primary outcome of the study was to compare the BP, HR changes during laryngoscopy and endotracheal intubation between oral clonidine and oral midazolam for the patients undergoing GA.

Secondary outcome was to evaluate the preoperative sedation status between these two drugs.

\section{Statistical analysis of data}

All the data were entered into Excel Spreadsheet and analyzed using statistical software 'Statistical Package for the Social Sciences (SPSS) and Statistica.' All variables were numeric and were taken as normally distributed. Comparison between groups: The test of statistical significance applied was Student's unpaired $t$ test. Within group comparison: The test of statistical significance applied was-repeated Measures analysis of variance (ANOVA) followed by Tukey's test for two time point comparisons if ANOVA returns $P<0.05$. Categorically variables were compared between-groups by Chi Square test. A two tailed $P<0.05$ was considered as significant and $<0.01$ as significant and $<0.001$ as highly significant.

\section{RESULTS}

Total 50 patients, aged between 18 and 60 years; of ASA status I and II scheduled to undergo different surgical procedure where duration of surgery and anesthesia is expected to be less than 2 hours were included in this study.

Table 1 shows that the demographic profile was comparable among the two groups of our patients and has no statistical significance $(P>0.05)$ and were quite similar with other research investigations and provide us the uniform platform to evenly compare the results obtained.

The comparison of SBP, DBP (Figures 1, 2 respectively) between the groups at various time points as seen in Table 2 and found to be

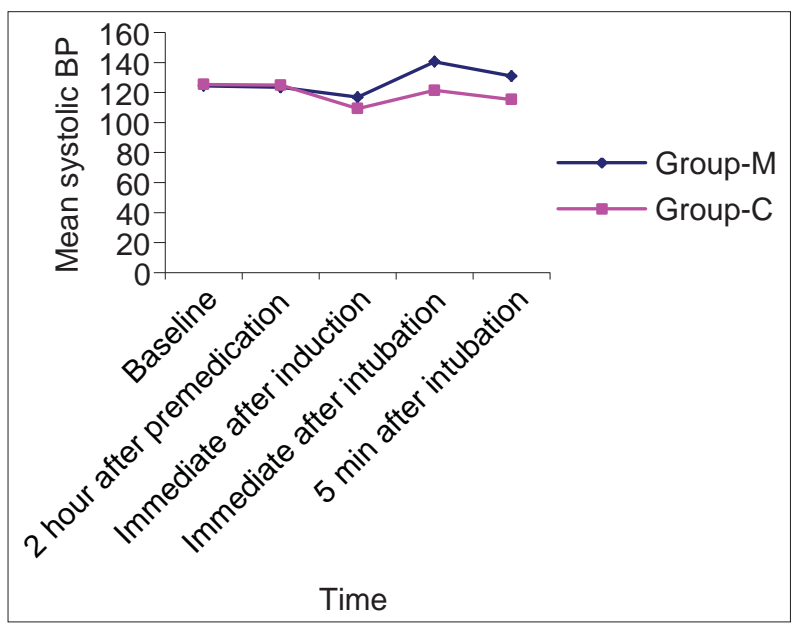

Figure 1: Comparison of systolic blood pressure changes comparable $(P>0.05)$ in the baseline and 2 hour after premedication values. However, immediate after induction, immediate after intubation, 5 min after intubation values were found to significantly different $(P<0.05)$ between the groups where Group M shows higher values.

The comparison of HR [Figure 3] and MAP [Figure 4] between the groups at various time points as seen in Table 3 was found to be comparable $(P>0.05)$ in the baseline and 2 hour after premedication values. However, immediate after induction, immediate after intubation, $5 \mathrm{~min}$ after intubation values were found to be significantly different $(P<0.05)$ between the groups where Group M shows higher values than Group C.

Preoperative sedation [Figure 5] were compared in the Table 4 and found that Group M (Midazolam) produced significantly $(P<0.05)$ better sedation than Group C (Clonidine).

Propofol requirement [Figure 6] for induction, in both the groups, was shown in the Table 5, which demonstrated that Midazolam is significantly helpful in induction and it reduces the dose of Propofol much more than Clonidine.

\section{DISCUSSION}

The goals to be achieved by premedication are relief of anxiety, sedation, analgesia, reduction in anesthetic requirement, prevention of autonomic stress responses, drying of airway secretions, reduction of gastric fluid volume, and increasing $\mathrm{pH}$. Ideal premedication fulfilling most of the goals without increasing side effects are still

\begin{tabular}{|c|c|c|c|}
\hline & Group M & Group C & $P$ value \\
\hline Age (year) & $38.76(9.38)$ & $42.24(10.45)$ & $>0.05$ \\
\hline Sex (M:F) & $12: 13$ & 13:12 & $>0.05$ \\
\hline Body Wt (kg) & $57.48(9.67)$ & $56.52(10.93)$ & $>0.05$ \\
\hline
\end{tabular}

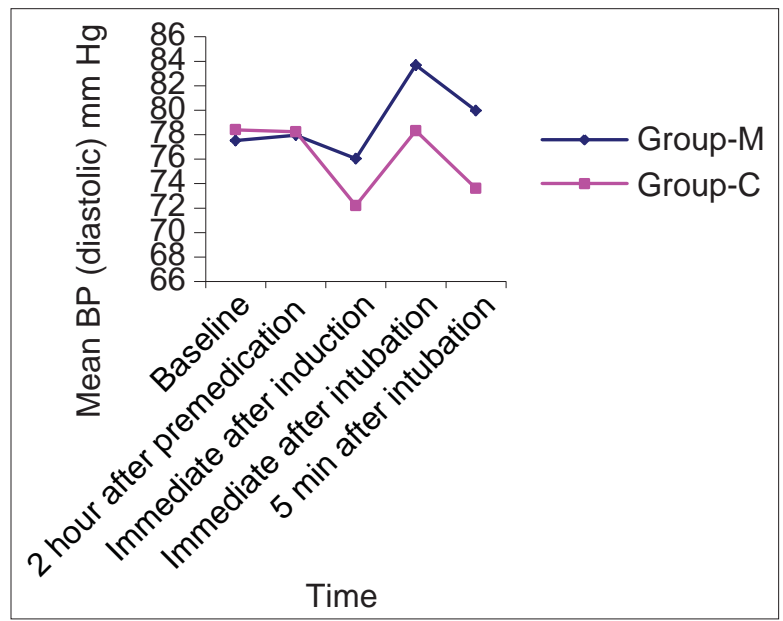

Figure 2: Comparison of diastolic blood pressure changes 


\begin{tabular}{|c|c|c|c|c|}
\hline & SBP & $P$ value & DBP & $P$ value \\
\hline \multicolumn{5}{|l|}{ Baseline } \\
\hline Group M & $124.52(3.33)$ & \multirow[t]{2}{*}{$>0.05$} & $77.52(2.50)$ & \multirow[t]{2}{*}{$>0.05$} \\
\hline Group C & $125.36(5.63)$ & & $78.4(3.86)$ & \\
\hline \multicolumn{5}{|c|}{$2 \mathrm{~h}$ after premed } \\
\hline Group M & $123.52(2.69)$ & \multirow[t]{2}{*}{$>0.05$} & $77.96(2.61)$ & \multirow[t]{2}{*}{$>0.05$} \\
\hline Group C & $124.96(5.52)$ & & $78.24(3.91)$ & \\
\hline \multicolumn{5}{|c|}{ Immediate after induction } \\
\hline Group M & $116.88(3.30)$ & \multirow[t]{2}{*}{$<0.01$} & $76.04(2.52)$ & \multirow[t]{2}{*}{$<0.05$} \\
\hline Group C & $109.32(6.30)$ & & $72.2(3.19)$ & \\
\hline \multicolumn{5}{|c|}{ Immediate after intubation } \\
\hline Group M & $140.56(3.65)$ & \multirow[t]{2}{*}{$<0.01$} & $83.68(3.17)$ & \multirow[t]{2}{*}{$<0.01$} \\
\hline Group C & $121.52(6.94)$ & & $78.32(3.25)$ & \\
\hline \multicolumn{5}{|c|}{5 min after intubation } \\
\hline Group M & $131(6.89)$ & \multirow[t]{2}{*}{$<0.001$} & $79.96(2.72)$ & \multirow[t]{2}{*}{$<0.001$} \\
\hline Group C & $115.36(7.3)$ & & $73.6(4.08)$ & \\
\hline
\end{tabular}

$\mathrm{SBP}=$ Systolic blood pressure, $\mathrm{DBP}=$ Diastolic blood pressure

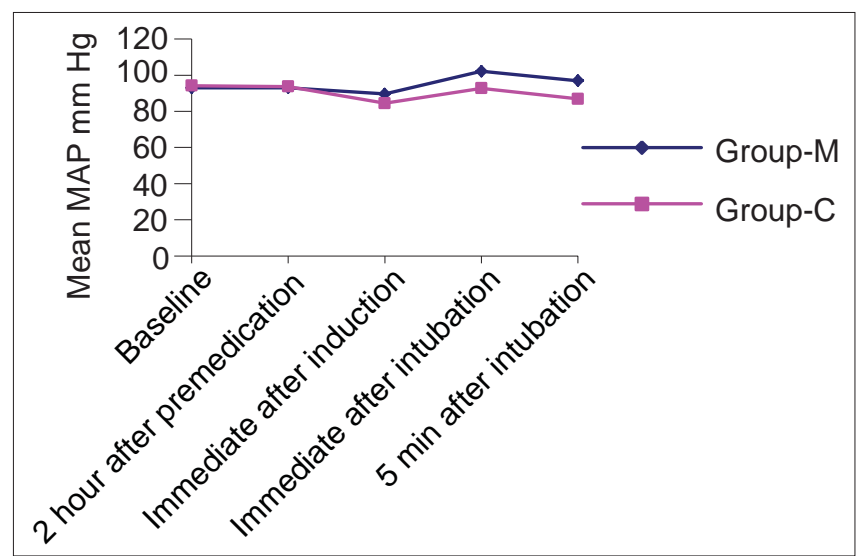

Figure 4: Comparison of mean arterial pressure changes

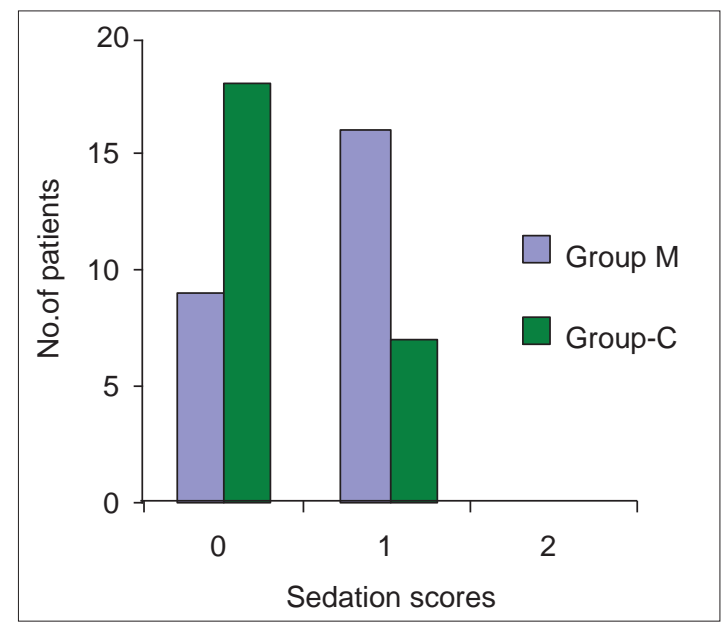

Figure 5: Comparison of preoperative sedation score

now in searching process.

Laryngoscopy and endotracheal intubation has become an

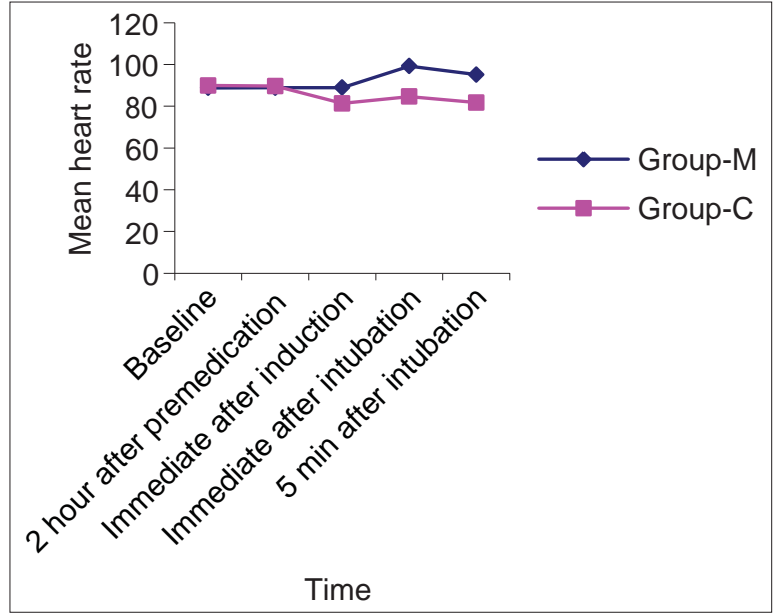

Figure 3: Comparison of heart rate changes

\begin{tabular}{|c|c|c|c|c|}
\hline & MAP & $P$ value & Heart rate (/min) & $P$ value \\
\hline \multicolumn{5}{|l|}{ Baseline } \\
\hline Group M & $93(2.08)$ & $>0.05$ & $88.8(5.27)$ & $>0.05$ \\
\hline Group C & $94.16(3.65)$ & & $89.92(5.16)$ & \\
\hline \multicolumn{5}{|c|}{$2 \mathrm{~h}$ after premed } \\
\hline Group M & $93.08(2.17)$ & $>0.05$ & $88.84(5.40)$ & $>0.05$ \\
\hline Group C & $93.72(3.96)$ & & $89.68(5.46)$ & \\
\hline \multicolumn{5}{|c|}{ Immediate after induction } \\
\hline Group M & $89.64(2.31)$ & $<0.001$ & $88.89(4.26)$ & $<0.001$ \\
\hline Group C & $84.48(3.19)$ & & $81.32(7.49)$ & \\
\hline \multicolumn{5}{|c|}{ Immediate after intubation } \\
\hline Group M & $102.12(2.53)$ & $<0.01$ & $99.24(5.46)$ & $<0.001$ \\
\hline Group C & $92.72(3.61)$ & & $84.64(7.57)$ & \\
\hline \multicolumn{5}{|c|}{5 min after intubation } \\
\hline Group M & $96.92(3.25)$ & $<0.001$ & $95.16(5.38)$ & $<0.01$ \\
\hline Group C & $86.84(3.69)$ & & $81.72(7.58)$ & \\
\hline
\end{tabular}

MAP=Mean arterial pressure

Table 4: Comparison of mean pre-operative
sedation score
\begin{tabular}{lccc}
\hline Group & Sedation score-0 & Sedation score-1 & Sedation score-2 \\
\hline M & 9 & 16 & 0 \\
C & 18 & 7 & 0 \\
$P$ value & & $<0.05$ & \\
\hline
\end{tabular}

essential component of standard general anesthesia. It leads to sympatho-adrenal stimulation. As a result of this, definite hemodynamic changes such as tachycardia, rise of BP and sometimes arrhythmias, acute coronary syndromes (ACS) have been observed.

Since long anesthesiologists have been putting efforts to find out the drugs that can prevent the exaggerated cardio-vascular pressure response during laryngoscopy and endotracheal intubation. The need is more felt when patients with end organ damage associated with pre-existing hypertension, ischemic heart disease, left ventricular hypertrophy, and cardiac failure and cerebro-vascular diseases 


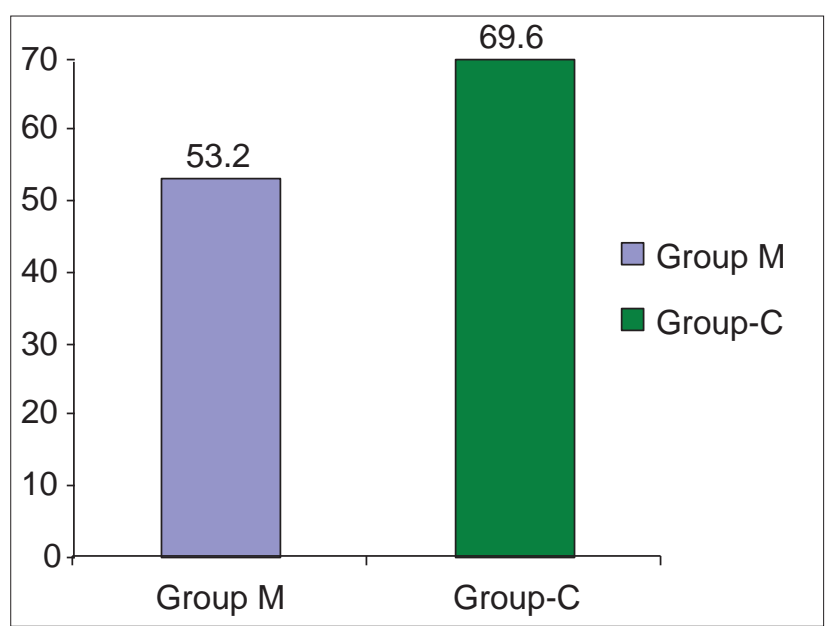

Figure 6: Comparison of induction dose of Propofol

present themselves for an emergency surgery or elective non-cardiac surgery. Hence, attenuation of the cardio-vascular response to the laryngoscopy and endotracheal intubation has got a role in preventing the peri-operative or post-operative complications in this group of patients.

$\alpha_{2 \mathrm{~A}}$ agonist clonidine, which has long been used as anti hypertensive in medical practice, is recently proved to have some beneficial premedicating effects like sedation, ${ }^{[17,18]}$ reduction of dose of induction agent, ${ }^{[19,20]}$ attenuation of laryngoscopic stress response, ${ }^{[17,21]}$ antisialagogue action, ${ }^{[17,22]}$ and postoperative analgesia. ${ }^{[17,23,24]}$ Prototype benzodiazepine, midazolam is among the most popular drugs used for premedication. In the present study, premedicating action of oral clonidine $(4 \mathrm{mcg} / \mathrm{kg})$ was compared to that of oral midazolam $(0.5 \mathrm{mg} / \mathrm{kg})$.

Fifty ASA Grade I and II patients of either sex, undergoing GA were selected for this study after thorough pre-operative evaluation and taking informed consent. Age range of the patients was between 18 years and 60 years. The patients were randomly divided into two equal groups of 25 patients each.

Group-C patients were to be received clonidine $4 \mathrm{mcg} / \mathrm{kg}$ orally and Group-M patients were to be received $0.5 \mathrm{mg} / \mathrm{kg}$ midazolam orally.

No statistically significant difference was observed in age, sex, body weight between two groups $(P>0.05)$ [Table 1].

In the pre-operative room baseline $\mathrm{HR}$, SBP, DBP, and MAP were recorded. Group-M and group $\mathrm{C}$ were comparable in respect to the distribution of the patients in different ranges of HR, SBP, DBP, and MAP $(P>0.05)$ [Tables 2 and 3].

Pre-operative sedation was assessed and scored as in Table 6. Patients who were non-communicative when asked for due to deep sedation were to be excluded from this study.

In this study, there was a significant difference in pre-operative sedation between two groups $(P<0.05)$ and midazolam $(M)$ caused significantly better sedation than clonidine (C) [Table 4].

Table 5: Comparison of mean induction dose of
propofol between two groups
\begin{tabular}{lcc} 
Group & Mean induction dose of propofol $(\mathbf{m g})$ & $\boldsymbol{P}$ value \\
\hline $\mathrm{M}$ & $53.2(4.76)$ & $<0.0001$ \\
$\mathrm{C}$ & $69.6(7.89)$ & \\
\hline
\end{tabular}

\begin{tabular}{ll} 
Table 6: Coring system for preoperative sedation \\
and 2 hour after premedication & 0 \\
\hline Awake and initiating conversation himself & 1 \\
Awake but noncommunicative & \\
(spontaneously, but responded when asked for) & 2 \\
Drowsy quiet and nonncommunicative \\
(spontaneously, ut responded when asked for)
\end{tabular}

Patients who were non-communicative when asked for due to deep sedation were to be excluded from this study

Midazolam produced this sedative action by virtue of its gamma-aminobutyric acid (GABA) potentiating action. ${ }^{[25]}$ The sedative effects of clonidine appeared to be mediated by central $\alpha_{2 \mathrm{~A}}$ receptor stimulation. ${ }^{[17,18]}$

Patients were then taken to operation theatre. Essential monitors were attached. SBP, DBP, MAP, and HR were recorded before induction as 2 hour after premedication value. We observed that there was a marginal fall in mean SBP, DBP, MAP, and HR from baseline in group C. Except for a very small rise inMAP, DBP, HR in group $\mathrm{M}$ was also observed. These changes were not statistically significant in respect to baseline within the same group and the difference in values between the two groups was also statistically insignificant $(P>0.05)$ [Tables 2 and 3].

During induction patients were pre-oxygenated with $100 \%$ oxygen for 5 minutes and injection fentanyl $1 \mathrm{mcg} / \mathrm{kg}$ IV was given at the same time. After completion of pre-oxygenation Inj propofol was administered in a titrated dose till the loss of verbal contact. The mean induction dose of propofol was $69.6 \pm 7.89 \mathrm{mg}$ in clonidine group and $53.2 \pm 4.76 \mathrm{mg}$ in midazolam group, respectively. So, midazolam reduced induction dose of propofol in much more effective manner than clonidine [Table 5].

Hideyuki Higuchi et al., (2002) ${ }^{[26]}$ showed in a study that the propofol concentration required for LMA insertion in healthy male patients is reduced by premedication with $5.0 \mu \mathrm{g} / \mathrm{kg}$ oral clonidine. Gill PS also demonstrated $(2001)^{[27]}$ in a study that the midazolam reduces the dose of propofol required for induction of anesthesia and successful insertion of the laryngeal mask airway.

In our study, just immediately after induction there was a significant fall in HR, SBP, DBP, and MAP in both group M and C (except in group $\mathrm{M}$ where HR slightly increased after induction) but in group $\mathrm{C}$, it was also significantly lower than group $\mathrm{M}$ values [Tables 2 and 3].

Inj atracurium besylate $0.5 \mathrm{mg} / \mathrm{kg}$ was administered IV after induction to facilitate laryngoscopy and intubation. Hemodynamic parameters 
were recorded just after intubation and 5 minutes after that. Mean HR, SBP, DBP, and MAP were increased in both groups just after completion of laryngoscopy and intubation, but in group $\mathrm{C}$, it was still at a lower level than baseline values and was significantly less than group $\mathrm{M}$. The rise in the parameters in midazolam group was significant in respect to basal values (except DBP). These hemodynamic parameters came down to a lower level 5 minutes after intubation in both the groups but in midazolam group it was still higher than baseline and in clonidine group, the values were significantly less than baseline and less than midazolam also [Tables 2 and 3].

Our result was similar to that of Paris, Andrea et al., (2009) ${ }^{[28]}$ who concluded that Clonidine ( $150 \mu \mathrm{g}$ orally), but not midazolam $(7.5 \mathrm{mg}$ orally), augmented hemodynamic stability and partially blunted stress responses as determined by plasma adrenocorticotropic hormone (ACTH) levels.

This above hemodynamic changes were probably the result of the partial agonistic action of clonidine at central $\alpha_{2 \mathrm{~A}}$ adrenergic receptor. ${ }^{[17,21]}$ Animal study showed that the hypotensive action might also be caused by an action of clonidine on imidazole receptor ${ }^{[29]}$ in the rostral ventrolateral medulla. Midazolam has no direct action on sympathetic nervous system.

In the present study, no patient showed arrhythmia or respiratory depression or significant change in heart rate and blood pressure till 12 hours after the completion of surgery.

Similar result was found by Mikawa K, et al., (1993) ${ }^{[30]}$ who observed no clinically significant bradycardia or hypotension in patients receiving $4 \mathrm{mcg} / \mathrm{kg}$ or $2 \mathrm{mcg} / \mathrm{kg}$ oral clonidine or $0.4 \mathrm{mg} / \mathrm{kg}$ diazepam and atropine $0.03 \mathrm{mg} / \mathrm{kg}$ in each group.

Lisa Fazi et al., (2001) ${ }^{[16]}$ also found in a study on 134 children (of 4-12 yr) undergoing tonsillectomy that oral midazolam $(0.5 \mathrm{mg} / \mathrm{kg})$ and oral clonidine $(4 \mathrm{mcg} / \mathrm{kg})$ as a pre-anesthetic medication did not produced unwanted cardiovascular changes.

Similar result was also confirmed by Nicole Almenrader et al., $(2007)^{[15]}$ in another prospective open study in 64 children.

\section{CONCLUSION}

The major goals of premedication are relief of anxiety, sedation, analgesia, reduction in anesthetic requirement, prevention of autonomic stress responses, drying of airway secretions, reduction of gastric fluid volume, and increasing $\mathrm{pH}$. The study was conducted to evaluate the effects of oral clonidine $(4 \mathrm{mcg} / \mathrm{kg}$ ) on preoperative sedation, BP and HR changes during laryngoscopy and intubation, and side-effects in comparison to oral Midazolam $(0.5 \mathrm{mg} / \mathrm{kg})$ when both given 2 hours prior to induction of GA.

Hemodynamic parameters were noted 2 hours after premedication, just after induction, immediately after laryngoscopy intubation and 5 minutes after intubation. It was observed that midazolam (M) caused significantly better sedation than clonidine (C). The hemodynamic changes were found to be attenuated more in group clonidine $(\mathrm{C})$ than in group midazolam $(\mathrm{M})$ particularly immediately after laryngoscopy and intubation. No significant side effect was observed in any group till 12 hours of completing the procedure.

From the observations made in this study, the followings were concluded:

1. $0.5 \mathrm{mg} / \mathrm{kg}$ oral midazolam was more effective as pre-operative sedative than $4 \mathrm{mcg} / \mathrm{kg}$ oral clonidine as given 2 hours before induction of anesthesia.sedative than $4 \mathrm{mcg} / \mathrm{kg}$ oral clonidine as given 2 hours before induction of anesthesia

2. Hemodynamic stability was well maintained and the surge in BP and HR during laryngoscopy and intubation was better controlled by oral clonidine than oral midazolam

3. Neither $4 \mathrm{mcg} / \mathrm{kg}$ oral clonidine, nor $0.5 \mathrm{mg} / \mathrm{kg}$ oral midazolam produced significant side effects.

Finally, it can be asserted from this study that $\alpha_{2 \mathrm{~A}}$ agonist clonidine $4 \mathrm{mcg} / \mathrm{kg}$ oral is a better pre-anesthetic medication than prototype benzodiazepine, midazolam $0.5 \mathrm{mg} / \mathrm{kg}$ oral in regard to attenuation of laryngoscopic stress response. It can be used as an effective alternative to midazolam for pre-operative sedation, reduction in dose of Propofol during induction.

\section{Limitation of the study}

Perioperative drug level assay was not done. Invasive BP monitoring was not available. Analgesic, antisecretory, antiemetic effects of clonidine and side effects of both the drugs need further studies by other workers.

\section{REFERENCES}

1. Miller CD, Warren SJ. IV lignocaine fails to attenuate the cardiovascular response to laryngoscopy and tracheal intubation. $\mathrm{Br} J$ Anaesth 1990;65:216-9.

2. Tam S, Chung F, Campbell M. Intravenous lidocaine: Optimal time of injection before tracheal intubation. Anesth Analg 1987;66:1036-8.

3. Davies MJ, Cronin KD, Cowie RW. The prevention of hypertension at intubation. A controlled study of intravenous hydralazine on patients undergoing intracranial surgery. Anaesthesia 1981;36:147-51.

4. Turner DA, Shribman AJ, Smith G, Achola KJ. Effect of halothane on cardiovascular and plasma catecholamine responses to tracheal intubation. Br J Anaesth 1986;58:1365-70.

5. Helfman SM, Gold MI, Delkser EA, Herrington CA. Which drug prevents tachycardia and hypertension associated with tracheal intubation: Lidocaine, fentanyl, or esmolol? Anesth Analg 1991;72:482-6.

6. Korpinen R, Saarnivaara L, Siren K, Sarna S. Modification of the haemodynamic responses to induction of anaesthesia and tracheal intubation with alfentanil, esmolol and their combination. Can J Anesth 1995;42:298-304.

7. Thompson JP, Hall AP, Russell J, Cagney B, Rowbotham DJ. Effect of remifentanil on the haemodynamic response to orotracheal intubation. $\mathrm{Br}$ J Anaesth 1998;80:467-9.

8. Sharma S, Mitra S, Grover VK, Kalra R. Esmolol blunts the haemodynamic responses to tracheal intubation in treated hypertensive patients. Can J Anaesth 1996;43:778-82.

9. Gold MI, Brown M, Coverman S, Herrington C. Heart rate and blood pressure effects of esmolol after ketamine induction and intubation. Anesthesiology 1986;64:718-23.

10. Stoelting RK. Attenuation of blood pressure response to laryngoscopy and tracheal intubation with sodium nitroprusside. Anesth Analg 
1979;58:116-9.

11. Gallagher JD, Moore RA, Jose AB, Botros SB, Clark DL. Prophylactic nitroglycerin infusions during coronary artery bypass surgery. Anesthesiology 1986;64:785-9.

12. McMillan CO, Spahr-Schopfer IA, Sikich N, Hartley E, Lerman J. Premedication of children with oral midazolam. Can $\mathrm{J}$ Anesth 1992;39:545-50.

13. Wright PM, Carabine UA, McClune S, Orr DA, Moore J. Preanesthetic medication with clonidine. Br J Anaesth 1990;65:628-32.

14. Kariya N, Shindoh M, Nishi S, Yukioka H, Asada A. Oral clonidine for sedation and analgesia in a burn patient. J Clin Anesth 1998;10:514-7.

15. Almenrader N, Passarieillo M, Coccetti B, Haiberger R, Pietropaoli P. Premedication in children: A comparison of oral midazolam and oral clonidine. Pediatric Anaesth 2007;17:1143-9.

16. Fazi L, Jantzen EC, Rose JB, Kurth CD, Watcha MF. A comparison of oral clonidine and oral midazolam as preanesthetic medications in the pediatric tonsillectomy patient. Anesth Analg 2001;92:56-61.

17. Maze M, Tranquilli W. Alpha-2 Adrenoreceptor agonist: Defining the role in clinical anaesthesia. Anesthesiology 1991;74:581-605.

18. Tripathi KD. Essentials of Medical Pharmacology: Antihypertensive drugs. $6^{\text {th }}$ ed. p. 546.

19. Imai Y, Mammoto T, Murakami K, Kita T, Sakai T, Kagawa K, et al. The effects of preanesthetic oral clonidine on total requirement of propofol for general anesthesia. J Clin Anesth 1998;10:660-5.

20. Morris J, Acheson M, Reeves M, Myles PS. Effect of clonidine pre-medication on propofol requirements during lower extremity vascular surgery: A randomized controlled trial. Br J Anaesth 2005;95:183-8.

21. Lyons FM, Bew S, Sheeran P, Hall GM. Effects of clonidine on the pituitary hormonal response to pelvic surgery. Br J Anaesth 1997;78:134-7.

22. Hoffman BB. Catecholamine, sympathetic drug and adrenergic receptor antagonist. Goodman and Gilman's: The Pharmacological Basis of therapeutics. $11^{\text {th }}$ ed.; 2001. p. 216-34.

23. Bernard JM, Hommeril JL, Passuti N, Pinaud M. Postoperative analgesia by intravenous clonidine. Anaesthesiology 1991;75:577-82.

24. Eisennach JC, Lysak SZ, Viscomi CM. Epidural clonidine analgesia following surgery: Phase I. Anesthesiology 1989;71:640-6.

25. Mohler H, Fritschy JM, Rudolph U. A new benzodiazepine pharmacology. J Pharmacol Exp Ther 2002;300:2-8.

26. Higuchi H, Adachi Y, Arimura S, Nitahara K, Satoh T. Oral clonidine premedication reduces the EC50 of propofol concentration for laryngeal mask airway insertion in male patients. Acta Anaesthesiol Scand 2002;46:372-7.

27. Gill PS, Shah J, Ogilvy A. Midazolam reduces the dose of propofol required for induction of anaesthesia and laryngeal mask airway insertion. Euro J Anaesthesiol 2001;18:166-70.

28. Paris A, Kaufmann M, Tonner PH, Renz P, Lemke T, Ledowski T, et al. Effects of clonidine and midazolam premedication on bispectral index and recovery after elective surgery. Eur J Anaesthesiol 2009;26:603-10.

29. Zhang X, Aman K, Hokfelt T. Secretory pathways of neuropeptides in rat lumbar dorsal root ganglion neurons and effects of peripheral axotomy. J Comp Neurol 1995;352:481-500.

30. Mikawa K, Maekawa N, Nishina K, Takao Y, Yaku H, Obara H. Efficacy of oral clonidine premedication in children. Anesthesiology 1993;79:926-31.

How to cite this article: Das A, Saha TK, Majumdar S, Mandal RD, Mukherjee A, Mandal SK. Comparative evaluation of oral clonidine and midazolam as premedication on preoperative sedation and laryngoscopic stress response attenuation for the patients undergoing general anaesthesia. Int J Med Public Health 2013;3:200-6.

Source of Support: Nil, Conflict of Interest: None declared. 